\title{
QUALIDADE DE VIDA DE CLIENTES PÓS-INFARTO AGUDO DO MIOCÁRDIO
}

\author{
Client's Quality of Life After \\ Myocardial Infarction \\ Calidad de Vida de los Clientes \\ Pós-Infarto Agudo del Miocardio
}

Joselany Afio Caetano

Enedina Soares

\section{Resumo}

Objetivou-se neste estudo avaliar a qualidade de vida de clientes que sofreram infar to agudo do miocárdio. A amostra constou de 30 clientes selecionados pela busca em prontuários de uma unidade cardiológica, que nos permitiu a identificação e localização desses clientes, internados no ano de 2004. Para coleta de dados utilizamos a Escala de Qualidade de Vida de Flanagan e o tratamento estatístico com desvio-padrão. Os resultados mostraram maior índice de respostas nos níveis "indiferentes" a "pouco satisfeitos" em suas qualidades de vida. A relação interpessoal apresentou o mais alto índice de satisfação, contrariando o bem-estar físico e material, com o mais baixo índice de satisfação. Concluiu-se que a avaliação da qualidade de vida de clientes que sofreram infarto agudo do miocárdio se mostra comprometida, o que vem corroborar outros estudos anteriormente realizados.

Palavras-chave: Infarto do Miocárdio. Qualidade de Vida. Enfermagem.

\section{Abstract}

This study evaluates the quality of life of clients who suffered myocardial infarction. The sample consisted of 30 clients selected by search in medical records of a cardiac unit, which let us to identify and locate these clients, admitted in the year 2004. For the data collection was used the Quality of Life Scale of Flanagan and the statistic with standard deviation treatment. The results showed a bigger index of answers in the "indifferent" to "little satisfaction" levels in their quality of life. The interpersonal relation showed the higher index of satisfaction, against the physical and material wellness, with the lowest index of satisfaction. It was concluded that the client's quality of life evaluation that suffered myocardial infarction is compromised, witch comes to confirm other previous studies that was carried trough.

Keywords:

Myocardial Infarction. Quality of Life. Nursing.

\section{Resumen}

El objetivo del estudio fue evaluar la calidad de vida de los clientes que han sufrido infarto agudo del miocardio. La muestra ha consistido de 30 pacientes escogidos por la búsqueda en historias clínicas de una unidad cardiológica, que nos permitió la identificación y localización de estos clientes, internados en el año 2004. Para la colecta de los datos utilizamos la Escala de Calidad de Vida de Flanagan y el tratamiento estadístico con desvío medio. Los resultados muestran mayor índice de respuestas en los niveles "indiferentes" a "poco satisfechos" en sus calidades de vida. La relación interpersonal presentó el más alto índice de satisfacción, contrariando el bienestar físico y material, con el más bajo índice de satisfacción. Ha concluído que la evaluación de la calidad de vida de clientes que sufrieron infarto agudo del miocardio muéstrase comprometida, lo que viene a confirmar otros estudios anteriormente realizados.

Palabras clave:

Infarto Agudo del Miocardio. Calidad de Vida. Enfermería. 


\section{INTRODUÇÃO}

0 conceito de qualidade de vida é relativamente recente e decorre, em parte, de novos paradigmas que têm influenciado as políticas e as práticas de saúde nas últimas décadas. Consoante a essa mudança de paradigma, a qualidade de vida passou a ser um dos resultados esperados tanto das práticas assistenciais quanto das políticas públicas para o setor da promoção de saúde e da prevenção de doenças ${ }^{1}$.

0 termo qualidade de vida é amplo e inclui uma variedade maior de condições que podem afetar a percepção do indivíduo, seus sentimentos e comportamentos relacionados com o seu funcionamento diário, incluindo a sua condição de saúde e as intervenções médicas.

A satisfação com a vida e sensação de bem-estar pode, muitas vezes, ser um sentimento momentâneo. Porém, acreditase que $o$ investimento na conquista de uma vida com qualidade pode ser construído e consolidado em um processo que inclui a reflexão sobre o que é definitório para sua qualidade de vida e o estabelecimento de metas a serem atingidas, tendo como inspiração o desejo de ser feliz.

Qualidade de vida (QV), em seu sentido geral, aplica-se ao indivíduo aparentemente saudável do ponto de vista físico e diz respeito ao seu grau de satisfação com a vida nos múltiplos aspectos que a integram: moradia, transporte, alimentação, lazer, satisfação/ realização profissional, vida sexual e amorosa, bom relacionamento com outras pessoas, liberdade, autonomia e segurança financeira. A qualidade de vida pode estar vinculada ao estilo de vida, incluindo padrão de alimentação, prática de atividades físicas, não-aderência a hábitos, como o cigarro, e a forma como encara o trabalho, a família e as chamadas "tensão de vida moderna"2.

Avaliar a QV de pessoas com doenças crônicas tem sido uma maneira de determinar o impacto do cuidado de saúde quando a cura não é possível. São considerados importantes aspectos de avaliação dos resultados dos procedimentos terapêuticos não apenas os aspectos relacionados à redução dos sintomas e prolongamento da vida, mas, também, os relacionados à sobrevida do doente e como a QV se apresenta para ele próprio e para a sociedade ${ }^{3}$.

Estudiosos desta temática apontam três razões que explicam a ênfase dada à qualidade de vida relacionada às doenças cardiovasculares, que justificam a preocupação em aferi-la: primeiro, o dilema das intervenções que, embora prolonguem a vida, comprometem sua qualidade; segundo, a relação que há entre os efeitos de uma droga sobre a qualidade de vida e a aderência do paciente à prescrição; e terceira, a aferição da validade, do ponto de vista econômico de uma dada intervenção². A importância da aferição da qualidade de vida afigura-se, pois, como inquestionável, principalmente nas doenças crônicas e incuráveis, como é o caso da maior parte das enfermidades cardiovasculares ${ }^{4}$. Por isso, cada vez mais são valorizadas as avaliações do impacto que uma nova terapêutica promove na qualidade de vida de um indivíduo.

Entendemos que a avaliação da qualidade de vida em pacientes com infarto do miocárdio tem a ver mais com os benefícios do que com os eventuais prejuízos da intervenção terapêutica. 0 que se vai medir é o quanto a insuficiência cardíaca impede ou dificulta a vida do paciente, pois esses portadores desenvolvem mecanismos para tentar diminuir os desconfortos que o tratamento lhes ocasiona e, dependendo da intensidade, acabam por afetar o seu estilo de vida. A escolha de um instrumento holístico para avaliar a QV nesta clientela é importante. A Escala de QV de Flanagan ${ }^{5}$ é um dos instrumentos de avaliação.

A enfermagem sempre teve e terá grandes preocupações com os cuidados prestados a uma pessoa em uma variedade de situações relacionadas à saúde, como o estado geral, 0 bem-estar, a qualidade de vida, dentre outras. Esse cuidado inclui papéis significativos na educação para a saúde, dentro da promoção da saúde, e a prevenção de doenças, bem como o cuidado individual do paciente, visto que este é 0 maior responsável pela manutenção de sua saúde e prevenção das doenças ${ }^{6}$.

A enfermagem é co-participante direta na difusão de medidas preventivas à população, por incluir, em suas principais atribuições, a atenção primária à educação em saúde, atividades educativas, informativas e interativas direcionadas à população. Portanto, a implementação de estratégias baseadas na promoção de um estilo de vida saudável requer esforço coordenado entre os provedores de cuidados com a saúde, tais como médicos, enfermeiros, nutricionistas e fisioterapeutas, odontólogos, o sistema escolar, outros órgãos governamentais, a indústria como a de alimentos e a farmacêutica.

Diante destas considerações, objetivou-se para este estudo identificar as dimensões da qualidade de vida afetadas pelos pacientes pós-infarto agudo do miocárdio, tendo em vista a melhoria da assistência prestada por profissionais de saúde após a alta hospitalar.

\section{METODOLOGIA}

Trata-se de um estudo descritivo, exploratório, realizado com pessoas que sofreram infarto agudo do miocárdio, usuários do Sistema Único de Saúde (SUS), atendidos em hospital de referência estadual em doenças torácicas e cardiovasculares, situado na cidade de Fortaleza-CE.

Participaram do estudo 30 clientes que sofreram infarto agudo do miocárdio - IAM, residentes da cidade de Fortaleza/ CE e que aceitaram contribuir com a pesquisa. A seleção dos participantes deveu-se aos registros de entrada na unidade de cardiologia clínica do hospital em estudo, nos quais foram levantados os números dos prontuários com historia de IAM, internados no ano de 2004. Por meio desses registros podemos localizar, no Serviço de Arquivo Medico - SAME, 30 prontuários contendo as informações que nos propiciaram a identificação e a localização desses clientes.

Para coleta de dados, utilizamos, como instrumentos, um roteiro de entrevista composta de duas partes: a primeira, com dados de identificação e sociodemográficos e a segunda, com aplicação da Escala de Qualidade de Vida (EQV) de Flanagan, na qual estão contidos os itens conceituais da qualidade de 
vida e representadas em cinco dimensões: bem-estar físico e material; relação com outras pessoas; atividades sociais, comunitárias e cívicas; desenvolvimento pessoal e realização; recreação.

Essas dimensões são mensuradas através de quinze itens nos quais os respondentes têm sete pontos que variam entre: $1=$ extremamente insatisfeito, 2 = bastante insatisfeito; 3 $=$ insatisfeito; $4=$ nem insatisfeito, nem satisfeito; $5=$ satisfeito; $6=$ bastante satisfeito e $7=$ extremamente satisfeito. A pontuação máxima alcançada na avaliação da qualidade de vida proposta por Flanagan é de 105 pontos, e a mínima, de 15 pontos, que refletem baixa qualidade de vida ${ }^{5}$.

Para aplicação das entrevistas e da Escala da Qualidade de Vida de Flanagan, foram realizadas visitas domiciliares. Os dados coletados foram tratados em conformidade com as alternativas mais adequadas ao conteúdo dos instrumentos utilizados e apresentados em gráfico e quadro e análise da distribuição das características dos escores da qualidade de vida de acordo com a Escala, assim como dos escores da média e do desvio-padrão obtidos por itens da escala em consonância com o referencial teórico.

Vale ressaltar que os princípios éticos contidos na Resolução 196/96 do Conselho Nacional de Saúde, que trata da pesquisa com seres humanos, foram devidamente respeitados, garantindo-se o anonimato dos partícipes e sua saída da pesquisa quando considerasse necessário.

\section{RESULTADOS}

\section{Caracterização da amostra - Dados de identificação e sociodemográficos}

Para que pudéssemos caracterizar os participantes deste estudo, selecionamos algumas informações que julgamos pertinentes e que nos possibilitaram trabalhar os dados obtidos sob os enfoques planejados.

0 estudo foi realizado com a participação de 30 clientes acometidos com IAM, sendo 19 (63,3\%) do sexo masculino e $11(36,7 \%)$ do sexo feminino. Estudos realizados recentemente mostraram que doenças da artéria coronária atingem mais homens do que mulheres; entretanto, depois da menopausa, a incidência em mulheres aumenta rapidamente e passa a ser quase igual a dos homens jovens na faixa etária de 30 anos ou menos ${ }^{7,8}$.

A prevalência de IAM no sexo masculino em relação ao feminino pode ser atribuída a uma menor tendência trombolítica e à proteção hormonal natural, determinada pelos níveis de estrogênios, cujos mecanismos estão relacionados à interferência nos níveis de lipídios plasmáticos (elevação do nível de HDL-colesterol e redução do LDL-colesterol), efeito direto na parede do vaso, reduzindo a captação de lipídios e a vasodilatação, com melhoria da pulsatilidade arterial| .

Com relação à incidência de IAM em mulheres, cientistas revelaram que devem ser consideradas, além da causa fixa, que é a proteção hormonal, também as causas modificáveis, como, por exemplo, maior atenção às enfermidades e, consequentemente, maior utilização dos serviços de saúde, comportamento e condutas menos agressivas, hábitos mais saudáveis (sem o consumo de álcool e tabaco) e menor exposição aos riscos do trabalho ${ }^{9}$.

A partir da década de 1980, este perfil vem mudando. A ocorrência entre as mulheres vem crescendo significativamente pelas transformaç̃̃es sociais e culturais que estimularam a maior participação da mulher no mercado de trabalho e a progressiva adoção de hábitos nocivos à saúde - tabagismo e etilismo que, aliados ao estresse e ao uso de contraceptivos orais, representam sérios fatores de risco. 0 excesso de adrenalina, gerado pela ansiedade e pela fadiga constantes, acelera o ritmo cardíaco, contrai as artérias e favorece a formação de coágulos, desencadeando, portanto, a angina e o $\mathrm{AMM}^{8}$.

A doença do coração nas mulheres é uma preocupação mundial, por ser a primeira causa de morte feminina nos países mais desenvolvidos. Estatísticas nos Estados Unidos mostram que, em 1989, cerca de 329 mil mulheres morreram de doença cardiovascular. Esse número equivale a $3,8 \%$ do total de mortes entre as mulheres naquele ano. No Brasil, $40 \%$ das pessoas com problemas cardíacos são mulheres, sendo a proporção de morte de 3,5 homens para 1 mulher. Apesar das mudanças de hábitos, a probabilidade de o coração feminino infartar é quatro vezes menor do que o coração masculino, graças à ação do estrogênio ${ }^{10,11}$.

Neste estudo a faixa etária foi de 48 a 78 anos, com média de idade de 62 anos; com relação ao estado civil, os casados predominaram nesta amostra, com $24(80,0 \%)$; seguidos pelos viúvos, três (10,0\%); separados, dois (6,7\%); e solteiros, um $(3,3 \%)$. Dados estatísticos verificados em outros estudos ${ }^{12,13}$ mostraram que há relação entre estado civil e os processos de morbidade e mortalidade por doenças crônico-degenerativas. A freqüência das doenças eleva-se nos solteiros e a mortalidade é maior entre viúvos, divorciados e solteiros. A relação entre estado civil e saúde é vulnerável a mudanças, na proporção em que outros tipos de relacionamentos sejam incorporados ao conceito de vida conjugal. Na sociedade atual, o cônjuge tem papel fundamental na reabilitação do cliente coronariopata. Esse apoio favorece aquele que tem parceiro fixo, mesmo porque terá mais chances de reintegração em menor tempo ${ }^{9}$.

As questões religiosas têm grande influência nesse momento da vida, de forma que $100 \%$ da população pesquisada (30) demonstraram afinidade com algum tipo de atividade ou prática religiosa, predominando o engajamento na religião católica com $25(83,3 \%)$, seguida da religião evangélica, cinco $(16,7 \%)$. Quanto às razões para a ocorrência desse fato, verifica-se que a prática de alguma religião permite estabelecer um elo entre as limitações e 0 aproveitamento de suas potencialidades, ou quando isso não ocorre, ajuda-o a vencer com mais facilidade essa fase que está vivenciando ${ }^{12}$.

A tarefa de lidar consigo mesmo e a busca de paz interior parece ter um significado maior para a aceitação das condições de vida e de encontrar conforto na perda e na dor. A prática religiosa também tem papel social na convivência entre as pessoas, na terapia de relaxamento e nos problemas, pela conquista do céu diante da iminência da morte. A religião serve também de lenitivo à incapacidade humana de enfrentar 
fracasso e sofrimento - entrega-se tudo a Deus e aí vem o consolo. Os movimentos religiosos promovem um preenchimento saudável do tempo e de convivência social. Representam um compromisso na regularidade de uma ação agradável que serve de estímulo à pessoa com vistas à participação social ${ }^{13}$.

A moradia e a convivência têm sido a grande preocupação, porém, nesta amostra. Constatou-se que $20(66,7 \%)$ possuem casa própria, significando que a maioria acumulou ao longo dos anos algum patrimônio; três $(10,0 \%)$ residem em casa alugada; dois $(6,7 \%)$ moram com os filhos, e cinco $(16,7 \%)$ residem na casa de outras pessoas. Possuir casa própria dá, acima de tudo, segurança e autonomia. Morar no que é seu e não ser hóspede tem forte valor significativo no processo de relacionamento familiar. Constatou-se que 24 (80,0\%) vivem com os seus cônjuges; por outro lado, cinco $(16,7 \%)$ convivem com outros familiares e um $(1,3 \%)$ vive sozinho.

Outro fator de relevância para a caracterização da amostra é a renda familiar dos seus integrantes. Agrupamos estes dados em quatro segmentos, tomando como base o salário mínimo nacional vigente ( $R \$ 260,00$, em 2005). Verificamos que 26 $(86,7 \%)$ dos clientes sobrevivem com um a três salários mínimos e somente dois $(6,7 \%)$ informaram ter renda mensal superior a três salários mínimos.

Observamos que os aposentados constituem o maior grupo - 21 (70,0\%); seguidos de outras atividades - sete (23,3\%); e doméstica - dois (6,7\%). Incluídas na amostra estão outras categorias cujo esforço físico desempenhado é considerado de maior intensidade, como os profissionais de serviços gerais, quatro $(13,3 \%)$, e os pedreiros, três $(10,0 \%)$. Entende-se que o trabalho físico que produz exercícios sistemáticos estimula o miocárdio tornando-o menos vulnerável aos agravos isquêmicos. Ressalta-se também que os indivíduos habitualmente voltados para o desenvolvimento de atividades que exigem gastos energéticos significativos conseguem reduzir a influência dos fatores de risco com relação à mortalidade coronária9 .

0 grupo que merece destaque é o dos profissionais que trabalham no período da noite, por vezes, inclusive, sem a compensação adequada do repouso necessário, ou excedendo as horas trabalhadas em duplas jornadas contínuas. $\mathrm{Na}$ realidade, podemos constatar que esta amostra é constituída por pessoas que não dispõem de condições sócio-econômicas para o custeio de despesas hospitalares, fazendo parte, portanto, da população usuária dos serviços públicos de saúde. Mesmo com o SUS garantindo o direito à saúde para todos, os cidadãos brasileiros têm sido vítimas da diminuição progressiva de recursos alocados para a garantia deste direito, e esta condição vem gerando uma assistência com pouca resolutividade e triagens contínuas ${ }^{14}$. A queda da qualidade da atenção prestada tem sido a principal fonte de desgaste e descrédito do SUS. É notório que a sociedade brasileira, com relação à opção de serviços de saúde, está classificada de acordo com o poder aquisitivo do usuário, ou seja, aqueles que podem escolher livremente profissionais e procedimentos e aqueles que são obrigados a recorrer às instituições públicas e, conseqüentemente, submeter-se ao descaso das filas, às listas de espera, ao sucateamento dos serviços e aos atendimentos impessoais ou inadequados ${ }^{11}$.

Observa-se que o acesso aos serviços de saúde não é igual ou universal e o poder aquisitivo vem se transformando em um determinante fator que assegura a poucos o direito à saúde. Esta realidade discriminatória e excludente, além de expor as fragilidades das políticas públicas de saúde e de tornar cada vez mais explícitas e cruéis as desigualdades sociais geradas pela concentração de renda, também interfere diretamente na qualidade de vida da sociedade, por ser a saúde considerada uma das dimensões fundamentais que possibilita ao ser humano uma vida plena e produtiva.

\section{Avaliação da Qualidade de Vida}

Na Escala da Qualidade de Vida de Flanagan, essa qualidade é alcançada pela interação de dimensões que se harmonizam segundo a concepção pessoal de cada indivíduo sobre suas condições de vida. Ela pode ser utilizada como atributo e também como variável, pois determina a existência e a continuidade das organizações (sistemas, processos, produtos e serviços) e a dos próprios indivíduos (vida) de uma comunidade (coletividade). 0 termo qualidade pode ser usado como valorização, comparação e caracterização na busca de estabelecer processo de juízo ${ }^{15}$.

A mensuração da qualidade de vida vem-se tornando importante na avaliação de tecnologias e terapêuticas utilizadas na área da saúde. Com a evolução da ciência, que envolve condutas clínicas e procedimentos cirúrgicos, problemas oriundos da idade e do status no processo saúdedoença tornaram-se um fator primordial na adoção de novas alternativas de tratamento, para a recuperação e a respectiva melhora da vida. 0 interesse de pesquisadores em transformar o conceito de qualidade de vida em uma medida quantitativa para uso em ensaios clínicos e em modelos econômicos é crescente, para que esta medida possa ser comparada entre diversas populações e patologias ${ }^{12}$.

Tomando-se como base a pontuação máxima alcançada na avaliação da qualidade de vida proposta por Flanagan, de 105 pontos, e a mínima, de 15 pontos, que refletem baixa qualidade de vida, podem-se observar, no Gráfico 1, a seguir, levando em conta os limites dos escores de 30-40, três pacientes neste limiar; nos limites de 41-50, somente um; 51-60, seis; 61-70, cinco; 71-80, nove e de 81-90, seis. Nenhum apresentou pontuação máxima, nem tampouco mínima, porém os limites que apresentaram maior número de pacientes foram no escore de 71 80, o que mostra, neste estudo, que a qualidade de vida entre os participantes era alta. Tal resultado foi semelhante ao encontrado por outros autores que avaliaram a qualidade de vida.

A qualidade de vida, além de ser ímpar, também é temporal, pois a vivência de uma determinada situação pode ou não proporcionar uma qualidade de vida momentânea ou por um período longo. Portanto, quem pode definir a qualidade de vida de uma pessoa é ela própria, vivendo e interconectando o interior com o exterior. Por isso, devemos ter consciência que a interconexão com o ambiente, a família e a sociedade pode causar mudanças relevantes na vida do portador de IAM. 
Gráfico 1 - Distribuição das características segundo escores totais na EQV*apresentada pelos clientes do Hospital de Messejana da cidade de Fortaleza-CE, 2005 - Escala de qualidade de vida, segundo Flanagan.

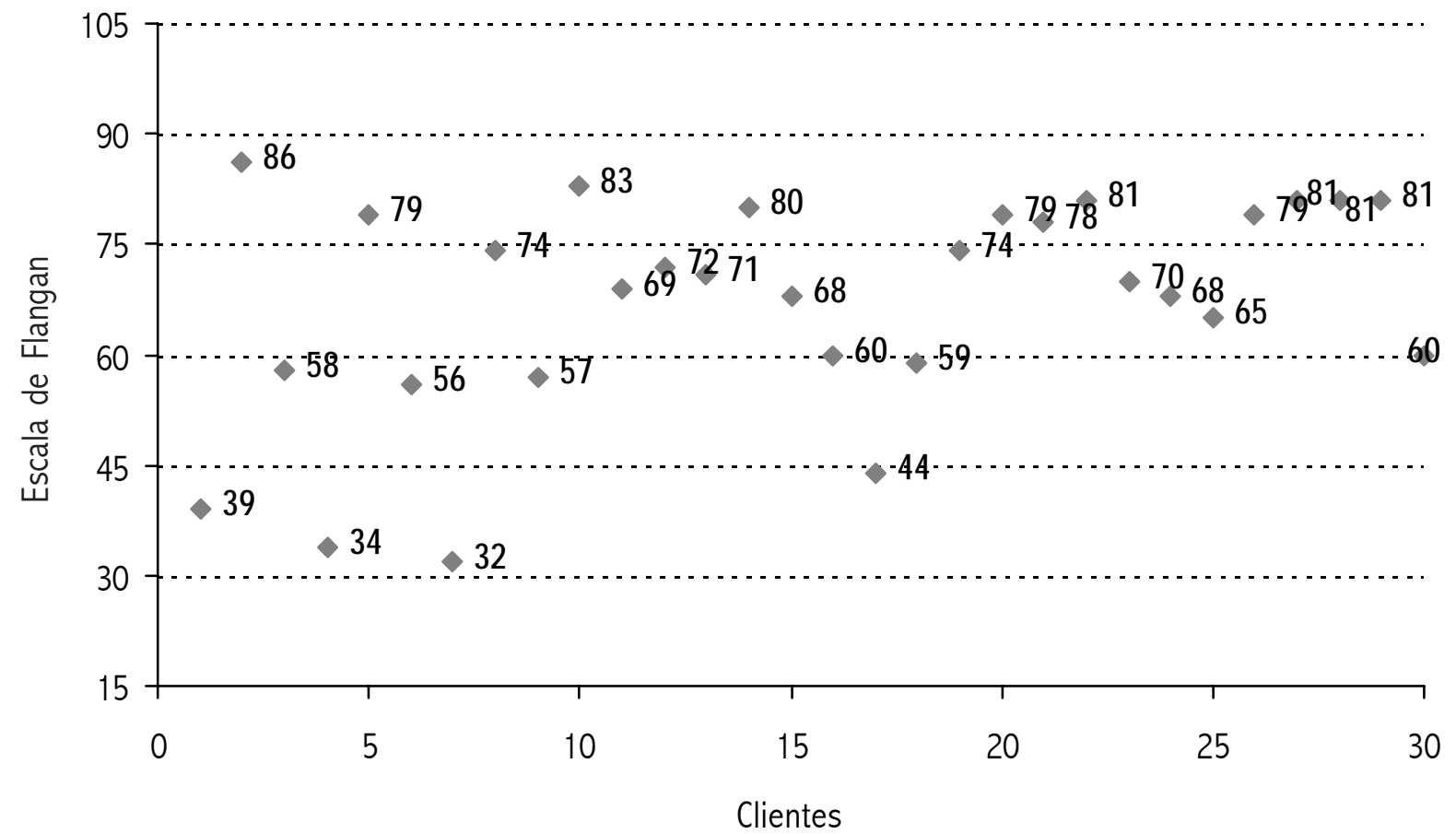

Pelo caráter multifatorial da doença coronariana, e sendo a saúde vista como um fenômeno multidimensional que envolve aspectos físicos, psicológicos, sociais e espirituais, é necessário entender que a doença física pode ser contrabalanceada por uma atitude mental positiva e por um apoio social, de modo que o estado global do indivíduo seja de bem-estar ${ }^{16}$.

Como pode ser observado no quadro 1 , a seguir, a média total da escala de qualidade de vida foi de 67,26 e a média de todos os itens foi de 4,48. Este resultado foi obtido somando todos os itens médios da escala - o resultado reflete que os participantes estão aproximadamente no grau 4-5, que com base nas respostas da escala de sete escores. 0 número 4 representa nem insatisfeito, nem satisfeito; já o 5 é satisfeito.

0 bem-estar físico e material, dimensão 1 da EQV de Flanagan, representada pelos itens "conforto material" e "saúde", apresentaram médias de 5,20 e 4,20; respectivamente. 0 conforto material está diretamente vinculado à renda - vinte e seis dos pesquisados recebem até três salários mínimos, como renda familiar.

Sentir a vida difícil tem a ver, também, com a escassez de recursos econômicos. Embora a renda seja um problema com o qual lidaram toda a vida, nesse momento se agudiza pela saída social do trabalho, pelo escasso valor da aposentadoria ou pensão, ou pelas dificuldades para conseguir, o que dizem eles, seus direitos. "Estar bem vigoroso", para eles, está relacionado com a possibilidade de ter, ser, poder e saber. 0 ter traz referência ao conjunto de necessidades básicas parcialmente resolvidas, a possibilidade de contar com bom estado de saúde e capacidade para realizar suas atividades de vida diária.
Possuir uma moradia própria gera uma sensação de bemestar, dá segurança e autonomia; alimentar-se bem, para eles, significa comer "tudo" do que gosta, sem restrições. A modificação da alimentação faz parte da terapia não farmacológica, pois a dieta inadequada pode comprometer mais ainda as coronárias; assim, essa modificação, por vezes, não é vista como parte do tratamento, deixando-os insatisfeitos e, às vezes, até deprimidos. Esta incompreensão pode estar relacionada com a falta de orientação sobre a doença e o tratamento, devendo, por conseguinte, ser realizada por médicos e enfermeiros logo após a estabilização da crise aguda do infarto ${ }^{17}$.

Verifica-se, portanto, que, na área da saúde, a vida se torna difícil em virtude das dificuldades para acessar o sistema de saúde, da ineficiência desse sistema, dos problemas para compra de remédios ou para fazer o tratamento, da ansiedade por não compreender sua doença ou pela enfermidade de um ser querido.

Nas relações interpessoais, representada pela dimensão 2 da EQV de Flanagan, observa-se que a média das respostas dos participantes no quesito relacionamento com a família foi 5,27, que se encontram satisfeitos. Registram-se aqui as expressões de afetividade percebidas nas respostas a este item, tendo algum cliente colocado a família como maior responsável pela sua recuperação. É de suma importância o apoio dos grupos, principalmente da família, dos filhos e amigos, em que o indivíduo pode se sentir intimamente aceito, respeitado e considerado, 0 que, sem dúvida, representa um fator de proteção para o coração ${ }^{14}$.

Na relação da criação dos filhos, as respostas apresentaram uma média de 5,63 , ou seja, os clientes não sentiram alterações 
Quadro 1:

Estatística descritiva das respostas dos participantes aos itens da Escala de Qualidade de Vida de Flanagan. Fortaleza/CE. 2005.

\begin{tabular}{|c|c|c|}
\hline \multirow[b]{2}{*}{ Dimensões/Itens da EQV de Flanagan } & \multicolumn{2}{|c|}{ Escores } \\
\hline & $\begin{array}{l}\text { Média } \\
\quad(\mathrm{x})\end{array}$ & $\begin{array}{l}\text { Desvio-Padrão } \\
\text { (s) }\end{array}$ \\
\hline $\begin{array}{l}\text { 1. Conforto material: casa, alimentação, } \\
\text { situação financeira. }\end{array}$ & 5,20 & 0,76 \\
\hline 2. Saúde: fisicamente bem e vigoroso(a) & 4,20 & 1,97 \\
\hline $\begin{array}{l}\text { 3. Relacionamento com pais, irmãos e outros } \\
\text { parentes: comunicação, visita e ajuda }\end{array}$ & 5,27 & 1,44 \\
\hline 4. Constituir família: ter filhos & 5,63 & 0,49 \\
\hline $\begin{array}{l}\text { 5. Relacionamento íntimo com o esposo(a), } \\
\text { namorado(a) ou outra pessoa relevante. }\end{array}$ & 3,57 & 1,96 \\
\hline $\begin{array}{l}\text { 6. Amigos próximos: compartilhar interesses, } \\
\text { atividades e opiniões. }\end{array}$ & 4,97 & 1,38 \\
\hline $\begin{array}{l}\text { 7. Voluntariamente, ajudar e apoiar a outras } \\
\text { pessoas }\end{array}$ & 5,47 & 0,68 \\
\hline $\begin{array}{l}\text { 8. Participação em associações e atividade de } \\
\text { interesse público }\end{array}$ & 4,50 & 1,53 \\
\hline $\begin{array}{l}\text { 9. Aprendizagem: freqüentar outros cursos para } \\
\text { conhecimentos gerais }\end{array}$ & 4,13 & 1,59 \\
\hline $\begin{array}{l}\text { 10. Autoconhecimento: reconhecer seus } \\
\text { potenciais e limitações }\end{array}$ & 3,53 & 1,83 \\
\hline $\begin{array}{l}\text { 11. Trabalho (emprego ou em casa): atividade } \\
\text { interessante, gratificante, que vale a pena. }\end{array}$ & 3,23 & 2,0 \\
\hline 12. Comunicação criativa & 4,53 & 1,61 \\
\hline 13. Participação em recreação ativa & 4,23 & 1,59 \\
\hline $\begin{array}{l}\text { 14. Ouvir música, assistir à TV ou cinema, } \\
\text { leitura ou outros entretenimentos. }\end{array}$ & 4,33 & 1,73 \\
\hline 15. Socialização: fazer amigos. & 4,47 & 1,74 \\
\hline
\end{tabular}

ou incapacidades. A família e os filhos são a primeira rede social do indivíduo, é nela que as relações acontecem e se desenvolvem? Em um estudo realizado ${ }^{18}$ sobre QV do diabético, 0 autor identificou que o grau de satisfação familiar com a vida está relacionado às condições de saúde, à relação familiar harmônica e à resolução de problemas financeiros, familiares e de trabalho.

0 relacionamento íntimo com companheiro apresentou-se prejudicado, com uma média de 3,57 , o que representa o ponto $3-4$, onde temos no número $3=$ insatisfeito e $4=$ nem insatisfeito, nem satisfeito. A ansiedade, a depressão, o medo de morrer, a simbologia do coração doente, a revisão dos valores vitais, baixa auto-estima e, conseqüentemente, o sentimento de impotência diante da vida, decorrentes da doença, são generalizados para a área sexual, gerando um sentimento de que não vai conseguir lidar com os eventos da vida, simbolizados pela incapacidade e insatisfação sexual ${ }^{18}$.

Quanto às relações com os amigos, as respostas apresentaram média de escore 4,97, quase 5 , satisfeito. Mesmo justificando o apoio de amigos para o enfrentamento do problema, das novas adaptações, ressaltamos, porém, a manifestação de sentimento como medo, limitações, dúvida, depressão, desânimo e mudanças de hábitos de vida, que retratam os desafios propostos ao ser humano pelo processo de adoecimento, pois a recuperação dos pacientes deve, necessariamente, ser complementada com outras ações que envolvem, além dos profissionais de saúde, a família e a comunidade, possibilitando a sua reintegração sócio-econômica ${ }^{19}$.

Na participação em atividades sociais, comunitárias e cívicas, registrou-se uma baixa média, 4,50, nem insatisfeito, nem satisfeito. Em relação à ajuda e apoio a outras pessoas, 5,47 , satisfeito. Portanto, foi possível constatarmos que a doença pode interferir no cotidiano dos indivíduos. Adoecer pode levar a um isolamento social, aumento da depressão e diminuição das expectativas de melhora, contribuindo para um sentimento de desesperança $a^{20}$. Há necessidade de compartilhar a experiência do adoecimento com outras pessoas que tenham passado por vivência semelhante, uma vez que a troca de informações poderia ser de grande valia nas conversas ou reuniões. 
No desenvolvimento pessoal e realização, dimensão 4 da EQV de Flanagan, o processo de aprendizagem, que apresentou baixa média de escore, 4,13, nem insatisfeito, nem satisfeito, o que pode ser interpretado como uma estagnação no processo de conhecimento, em que a maioria dos clientes, com mais de 60 anos, já se encontram "aposentados". No que diz respeito ao autoconhecimento, os clientes apresentaram média de 3,53, insatisfeito. A formação do indivíduo é refletida na vivência de situações estressantes, em que 0 indivíduo mostra a aceitação de seus limites e compreensão das perdas de suas capacidades ${ }^{5}$.

0 item trabalho apresentou 3,23 na média de escore, insatisfeito. A maior parte do grupo, 21, era inativa e atribuiu essa inatividade à doença. Esses achados reproduzem o que a literatura tem trazido sobre o impacto das doenças cardíacas na sociedade, que além de serem doenças com formas graves de manifestações clínicas, retiram precocemente o sujeito da vida produtiva, com conseqüências negativas para ele e para a sociedade ${ }^{12}$.

Quanto ao retorno às atividades domésticas, dois clientes relataram que não houve alteração significante em relação ao trabalho doméstico. Estudos mostram um percentual entre 52 a $70 \%$ de respostas positivas ao trabalho doméstico. Em relação às atividades profissionais, sete $(23,3 \%)$ se encontravam na ativa. As dificuldades em relação ao retorno ao trabalho ocorrem especialmente pelo cansaço físico e a dor. Um fator também observado, durante as entrevistas, é que os respondentes apresentavam-se pouco comunicativos, o que para eles pode dificultar a socialização. Entretanto, é nosso entendimento que a ajuda aos seus pares no processo de adaptação ao novo estilo de vida faz parte de sua personalidade, e não é em decorrência do infarto.

A recreação/atividades/sociais teve dimensão 5, representada pelos itens "participação em recreação ativa", média 4,23, nem insatisfeito, nem satisfeito; "ouvir música, assistir à TV ou ao cinema, leitura ou outros entretenimentos", média 4,33, nem insatisfeito, nem satisfeito; "socialização: fazer amigos", média 4,47, nem insatisfeito, nem satisfeito; com algumas restrições, desde o praticar esporte a sair de casa. A socialização/fazer amigos tem a ver com a capacidade de comunicação; é prejudicada não pelo agravo, mas, sim, pelas suas personalidades. Grande parte dos clientes continuou com sua atividade de lazer considerada passiva - cinemas, TV, leitura,entre outros, atividades de lazer que não requerem esforços.

Com relação às viagens e às atividades "ativas", como praticar algum tipo de esporte, os clientes demonstraram restrições. A maior parte do grupo, 21 (70\%), era inativa e atribuiu essa inatividade à doença.

Recreação com destaque para socialização, fazer amigos, apresentou uma média de escore 4,47, nem insatisfeito, nem satisfeito. 0 fato de receber apoio das pessoas queridas faz 0 doente sentir-se melhor. A doença, de certa forma, é também da família e dos amigos, e, quando essas pessoas estão presentes, dando apoio, a angústia é compartilhada, diluída ${ }^{12}$.

0 item ouvir música, assistir a TV, cinema, leitura ou outros entretenimentos apresentou uma média de escore de 4,33; participação em associações e atividades de interesse público, 4,23. Em nosso estudo foi possível constatar que a doença interfere no cotidiano dos indivíduos. Adoecer pode levar ao isolamento social, a um aumento da depressão e diminuição das expectativas de melhora, contribuindo para um sentimento de desesperança ${ }^{20}$.

$\mathrm{Na}$ dimensão bem-estar físico e material, o item saúde apresentou média de escore 4,20. A doença cardíaca é para muitos dos nossos entrevistados fator limitante para ter uma "vida normal", pois sabe-se que as doenças cardiovasculares podem levar a uma forte tensão, à medida que impingem outros desafios. Surgem as novas incumbências, como fazer regime e tomar medicação diariamente, além dos medos que podem aparecer em alguma fase da doença, como morrer ou evoluir para alguma deficiência.

No item conforto material, nota-se um escore 5,20, satisfeito, pois, para os nossos entrevistados, ter uma casa própria representa segurança e autonomia.

\section{CONCLUSÃO}

0 estudo revelou aspectos bastante importantes sobre a população estudada. Percebemos o quanto o infarto agudo do miocárdio afeta a qualidade de vida das pessoas, alterando diversos fatores de suas vidas.

Pelos resultados, a investigação permitiu reafirmar que, indubitavelmente, as doenças da artéria coronária atingem mais o homem $(63,3 \%)$ do que a mulher $(36,7 \%)$, tendo como predominante neste estudo a faixa etária de 48 a 70 anos. Também pudemos constatar que a amostra foi composta de clientes que se encontravam na faixa etária de 48 a 78 anos, dos quais $80 \%$ eram casados e conviviam com os seus cônjuges; os aposentados representaram 70\%; outras ocupações, 23,3\%; e domésticos, 6,7\%.

Pontuamos a questão salarial quando identificamos que somente $6,7 \%$ dos clientes tinham renda mensal de 3 a 5 salários mínimos e que $86,7 \%$, recebiam de 1 a 3 salários mínimos, contribuindo, de certa forma, para a determinação do nível de vida, uma vez que os clientes possuíam também índices menores de qualidade de vida. Apesar de apresentarem renda baixa, $66,7 \%$ possuíam moradia própria. Outro fator relevante observado foi a prevalência da religião católica (83,3\%), seguida da religião evangélica, $(16,7 \%)$.

A adequação da EQV de Flanagan apontou dados gerais acerca da qualidade de vida, tendo sido detectadas restrições para o cliente acometido pelo IAM, como, por exemplo, autoconhecimento e trabalho. Em relação à escala como um todo, o maior índice de respostas se posicionou no nível 4, "nem insatisfeito, nem satisfeito", a 5, "satisfeito", com suas qualidades de vida.

Os itens levantados como fontes de maior satisfação entre os participantes foram: conforto material; moradia, alimentação, situação financeira; relacionamento familiar (pais, o irmão e outros parentes); comunicação, visita e ajuda; constituir família: ter filhos; e, voluntariamente, ajudar e apoiar outras pessoas.

Quanto aos itens de insatisfação foram pontuados: relacionamento íntimo com esposo (a) ou outra pessoa 
relevante; autoconhecimento de seus potenciais e limitações; o trabalho (emprego ou em casa) como atividade gratificante, que vale a pena.

Na perspectiva de que qualidade de vida digna é um direito do homem, ressaltamos a missão dos profissionais da saúde, com destaque para o enfermeiro, que, através da continência e da sensibilidade do saber e da cidadania, podem contribuir para a transformação das pessoas e da sociedade. Por isso, é importante

\section{Referências}

1. Seidl EMF,Zannon CMLC. Qualidade de vida e saúde: aspectos conceituais e metodológicos. Cad Saúde Pública 2004 mar/abr; 20(2): 580-88.

2. Silva MAD, Sousa AGMR, Schargodsky H. Fatores de Risco Para Infarto Agudo do Miocárdio no Brasil. Estudo FRICAS. Arq Bras Cardiol 1998 nov; 71(5): 667-75.

3. Dantas RAS, Góis CFL, Silva LM. Utilização da versão adaptada da escala de qualidade de vida de Flanagan em pacientes cardíacos. Rev Latino-Am Enfermagem 2005 jan/fev; 13(1): 15-20.

4. Romano BW. Psicologia e cardiologia: encontros possíveis. São Paulo (SP): Casa do Psicólogo; 2001.

5. Flanagan JC. Measurent of quality of life: current state of the art. Arch Phys Med-Rehabil. 1982 Mar/Abr; 63(2): 56-59.

6. Ellis JR, Hartley CL. Enfermagem contemporânea: desafios, questões e tendências. Tradução de Maria Virgínia Godoy da Silva. $5^{\text {a }}$ ed. Porto Alegre (RS): Artmed; 1998.

7. Lima CAS. Ser mulher hoje: da ambivalência da vida à possibilidades de prevenção dos distúrbios cardíacos [monografia de graduação]. Sobral (CE): Universidade Estadual Vale do Acaraú/UVA. Enfermagem; 2000.

8. Hafe P, Andrade MJ, Fernando PB, Lopes C, Maciel MJ, Coelho R, et al. Fatores de risco de enfarto do miocárdio: um estudo de casocontrole no Porto. Rev Port Cardiol 1997 jun; 16(9): 695-702.

9. Oliveira SC. Doença cardíaca coronária: qualidade de vida do cliente revascularizado [dissertação de Mestrado]. Fortaleza (CE): Universidade Estadual do Ceará/. Saúde Pública; 1998.

10. Miranda LHS, Porto CC. Aspectos psicossociais das doenças cardiovasculares. In: Porto CC. Doenças do coração: prevenção e tratamento. Rio de Janeiro (RJ): Guanabara koogan; 1998.

11. Dever GEA. A epidemiologia na administração dos serviços de saúde. São Paulo (SP): Pioneira; 2001. que os profissionais de saúde se conscientizem da relevância dos programas de saúde preventiva para as doenças crônicodegenerativas e apliquem seus esforços na preservação da saúde e melhoria da qualidade de vida das pessoas sob seus cuidados.

A escala de Flanagan é um instrumento genérico de avaliação da qualidade de vida, que pode ser usada pelos profissionais de saúde, especialmente diante do cliente com doença crônica, afetando vários aspectos do cotidiano de sua vida.

12. Gallani MCBJ, Colombo RCR, Alexandre NMC, Bressan-Biojone AM. Qualidade de vida em pacientes coronariopatas. Rev Bras Enferm 2003 jan/mar; 56(1): 40-43.

13. Ide CAC, Schneck CA, Paz MO. Compartilhando uma vivência limite: as representações de familiares acerca do processo de hospitalização. 0 mundo da saúde 2000 jul/ago; 24(4): 278-83.

14. Ministério da Saúde(BR). Secretaria Nacional de Epidemiologia. Classificação brasileira de ocupação para o subsistema de informações sobre mortalidade. Brasília (DF); 1993.

15. Coelho Neto A. Planejamento estratégico para melhoria da qualidade de vida. Rio de Janeiro (RJ): Qualitymark; 1998.

16. Santos ZMA, Martins ZMDP, Valdés MTM. Doença cardíaca e a vivência da internação hospitalar para a pessoa idosa. Esc Anna Nery Rev Enferm 2005 ago; 9(2): 199-206.

17. Lomba M. Especialidades médicas. Olinca 2002;1.

18. Romano BW. Psicologia e cardiologia: encontros possíveis. São Paulo(SP): Casa do Psicólogo; 2001.

19. Sousa SMA. Qualidade de vida em clientes ostomizados. Texto \& Contexto Enferm 1999 set/dez; 8(3): 162-82.

20. Martins J, Bicudo MAV. A pesquisa qualitativa em psicologia: fundamentos e recursos básicos $2^{a}$ ed. São Paulo (SP): Moraes; 1994.

\section{Sobre as Autoras}

\section{Joselany Afio Caetano}

Enfermeira, Doutora Professora do Departamento de Enfermagem da Universidade Federal do Ceará. joselanyafio@uol.com.br.

\section{Enedina Soares}

Enfermeira, Livre Docente, Prof. aposentada da Universidade Federal do Rio de Janeiro UNII0. soaresene@ig.com.br. 